Article

\title{
Dealing with Multi-Level Governance and Wicked Problems in Urban Transportation Systems: The Case of Palermo Municipality
}

\author{
Guido Noto * and Carmine Bianchi \\ Department of European Studies, University of Palermo, Via Ugo Antonio Amico 2-4, Palermo 90134 , \\ Italy; E-Mail: bianchi.carmine@gmail.com \\ * Author to whom correspondence should be addressed; E-Mail: guido.noto@unipa.it; \\ Tel.: +39-333-357-6418.
}

Academic Editor: Thomas V. Huynh

Received: 11 February 2015 / Accepted: 23 June 2015 / Published: 30 June 2015

\begin{abstract}
Italian New Public Management (NPM) has been mainly characterized by a political orientation toward power decentralization to local governments and privatization of public companies. Nowadays, local utilities in Italy are often run by joint stock companies controlled by public agencies such as Regional and Municipal Administrations. Due to this transformation, these companies must comply with a set of diverse expectations coming from a wide range of stakeholders, related to their financial, competitive and social performance. Such fragmented governance increases the presence of "wicked" problems in the decision-making sphere of these entities. Given this multi-level governance structure, how do these agents influence public services performance? In recent years, coordination and inter-institutional joint action have been identified as possible approaches for dealing with governance fragmentation and wicked problems deriving from it. How can we adapt a performance management perspective in order to help us reform the system and so have a better collaboration between the stakeholders involved? In order to address and discuss these research questions, a case study will be developed. The case concerns AMAT, the local utility providing the public transportation service in the Municipality of Palermo (Italy). The result of this study is a dynamic model including a set of performance indicators that help us in understanding the impact of the governing structure on the system's performance.
\end{abstract}


Keywords: multi-level governance; performance management; wicked problems; system dynamics

\section{Introduction}

The New Public Management (NPM) paradigm was aimed at solving the shortcomings with regard to efficiency and effectiveness, which are intrinsic in the traditional bureaucratic approach [1]. This has been pursued by implementing a new set of practices, inspired by the private sector. The private sector perspective intended to shift attention onto results as the dominant focus; that implies the adoption of a Performance Management (PM) perspective. Performance Management can be defined as the cyclic process of identification of objectives, definition of actions and performance indicators, implementation, and monitoring in progress and ex-post the results achieved.

NPM reform was directed towards [1]: reducing or reversing government growth in terms of public spending and staffing; privatization and quasi-privatization of government institutions related to service provision; automation in production and distribution of public services; and the development of an international agenda focused on public policy and management issues, including intergovernmental cooperation.

Italy was not among the first countries to adopt this reform process. The main features of Italian NPM can be identified as privatization of public companies and decentralization of power to local authorities [2,3]. Structural devolution and quasi-privatization created, at the local level, a hybrid generation of service providers, halfway between being public and private. These utilities assumed the shape of joint stock companies owned or controlled by public agencies, such as municipalities. This generated a multi-level governance structure in which public services are provided by these subsidiaries through service contracts. The pressures and the constraints arising from different institutional levels, with diverse goals and service expectation, could render a top management intervention more complicated. These pressures, often pushing toward conflicting goals, are legitimized by ownership relations, asymmetric exchange of resources [4] and contracts. Eventually, such governance implies an administrative fragmentation that is depriving both the political and administrative bodies of levers of control and information, raising questions of accountability and capacity [5].

From 1997, and particularly after the reforms of 2005 and 2011, this situation has been made even more complicated by the introduction of the European Union "Stability and Growth Pact" (SGP). This is a rule-based framework for the coordination of national fiscal policies in the European Union. It was established to safeguard sound public finances, based on the principle that economic policies are a matter of shared concern for all Member States [6]. The adoption of this framework by the Italian Government determined serious limits to the expenses that local agencies can undertake in order to balance their budgets. Therefore, even these joint stock companies are under pressure from the local authorities to balance their budget with decreasing resources, and with the same level of quality standard of service expected (for example, Palermo's transportation utility service contract was reduced by $20 \%$ from 2011 to 2012; another reduction of $6 \%$ is forecast over the next three years). Furthermore, the Italian "Stability Pact" 2014 established new constraints for local authorities' subsidiaries. 
Administrative fragmentation and external constraints result in tensions between governance levels and competing policy priorities within and between agencies [7]. Particularly, the main issues which characterize the "pillarization" of the public sector, which followed the NPM reform, can be summarized as [8]: contradiction and tension between different policies, which decrease their effectiveness; duplication and contradiction of action programs, which negatively affect the use of resources; lack of synergy among stakeholders; and fragmented services provided to citizens.

The presence of several stakeholders participating in the governance, and the social environment surrounding it, make the problems affecting public services difficult to define and solve in agreement. In the case of urban transportation, different actors involved in the governance (i.e., local governments, companies, citizens, etc.) may have divergent interests or values that prevent agreement on the nature of the problems and how to deal with them. The literature named these kinds of problems "wicked" [7,9].

The term "wicked" does not means "evil", but refers to issues hard to define and manage due to the high complexity of the environment which they affect [7,10]. These issues often lead to counterintuitive behaviors when actions are taken to resolve them.

In order to better identify "wicked" problems, Rittel and Webber outlined ten of their characteristics [9]:

- There is no definitive formulation.

- They have no stopping rule (there are no criteria for framing the problem since they exist in open systems).

- Solutions are not true-or-false, but good or bad.

- It is not possible to test a solution.

- There is no opportunity to learn by trial-and-error (every trial counts).

- They do not have an enumerable set of potential solutions.

- Every problem is essentially unique.

- Every problem can be considered to be a symptom of another problem.

- The existence of a discrepancy representing a wicked problem can be explained in numerous ways.

- Decision makers have no right to be wrong (there is no tolerance of experiments that fail).

The old public management, meaning the traditional hierarchical forms of public administration, was unable to deal with these wicked issues mainly due to cultural and professional differences existing in the departments and functional areas of administrations. NPM was designed in order to overcome some of these shortcomings [1]. However, NPM was ill-suited to deal with wicked problems because it did not allow public agencies to overcome fragmentation and isolation of those actions and programs responsible for the complexity of these issues [7]. Because to this, since 1997, many countries have been attempting to increase their ability to deal with problems related to governance fragmentation through a new wave of reforms called "Joined-Up Government" (or "Whole of Government"), whose aim is the enhancement of coordination between different governance levels for improving public sector performance [5]. Joined-Up Government (JUG) "is an umbrella term describing various ways of aligning formally distinct organizations in pursuit of the objectives of the government of the day" [11]. This new reform trend proposes an inter-institutional governance approach, including new forms of coordination and power-distribution between the main actors involved, in order to tackle the "wickedness" coming from governance's fragmentation [5], and to neutralize or reduce its negative consequences on system service performance. 
Based on these considerations, understanding how governance structure influences these utilities' performance appears to be the first step in planning an institutional reform aimed at improving the ability to deal with the resultant "wicked" issues. It is therefore desirable to foster a JUG approach orientated at improving multi-level governance coordination, the adoption of a Performance Management approach.

Traditional Performance Management tools tend to focus on organization's performance from an overly static point of view in terms of time and space. The result is that these techniques, on the one hand, tend to stress excessively some functional areas of the organization (system) while ignoring others; and on the other hand, do not allow one to properly assess both determinants and consequences of performance with reference to the trade-offs existing between short- and long-term effects [12]. These tools, due to their static approach, do not help in understanding the process of accumulation and depletion of strategic resources and the performance drivers' effect on outcome indicators [13]. Therefore, PM have to be settled and framed through a systemic and dynamic perspective, taking into account not only the organizational boundaries, but also considering the values and interests of the major stakeholders involved.

A systemic (or "holistic") view is suggested by the literature $[7,9,14]$ in order to tackle "wicked" problems because it allows us to think broadly about social problems and possible solutions, considering major stakeholders' interests and expectations. The need to think systemically emerges from the complexity of the social environment. In complex situations, improving a component of a system not only does not necessarily improve the whole system [15], but it can generate imbalances that in the medium-long term may negatively affect the performance of the same system component.

An approach that allows us to take a broader perspective on performance issues is System Dynamics (SD). SD is indeed able to link a system's structure to its performance and vice-versa, often for the purpose of changing structure relationship so as to improve performance [15,16].

PM and SD have been combined in an approach named Dynamic Performance Management. This paper aims at applying this approach to defining a set of indicators to measure the urban transportation system's performance in a dynamic environment.

This study is based on an AMAT case study. The research has been conducted by investigating how the lack of coordination between the different governance levels is affecting the performance of this utility. After a first phase of system performance indicators identification, an analysis was conducted in order to explore whether AMAT management is fully responsible for each indicator, or whether there are some other governance players that also have a major influence.

The paper is structured as follows: in Section 2 the reader will be introduced to the adopted methodology and the reasons why it was chosen; the case study is analyzed in Section 3 where, first the governance structure of Palermo's transportation service is laid out, and afterwards all the analysis is carried out; Section 4 discusses the emerging results; lastly, the conclusions sum up the contributions given by the study and suggest some future perspectives.

\section{Research Methodology}

Wicked problems exist in contexts characterized by complexity, interconnectedness, pluralism and uncertainty [7]. 
A methodology able to deal with these characteristics is therefore desirable. As already mentioned, the chosen approach to exploring the case study is Dynamic Performance Management (DPM). This PM approach, so as to develop a performance analysis of a system, takes advantage of System Dynamics modeling.

System Dynamics could be defined as "a perspective and set of conceptual tools that enable us to understand the structure and dynamics of complex systems" [17]. Complex systems are difficult to examine because they lead to counterintuitive behaviors, which leave decision-makers unable to design and implement corrective action to prevent undesired behaviors [18]. Complex systems are characterized by multiple-loop structures [18]. A loop refers to the feedback process between two or more components of a system. Therefore, a basic activity of SD modeling is discovering and representing the feedback processes which determine the dynamics of a system $[17,18]$.

The focus of this paper is to describe the relationships between system strategic resources and end-results in order to build a set of performance indicators, which could improve the management-control activities of different governance levels. Such a system of indicators would help in making clear who has the levers of control in relation to certain resources, where there is a need for reforming the governance in the system by fostering coordination, and, finally, how to achieve a "good" trade-off for resource employment.

With regard to this, a SD approach can benefit from the adoption of a Performance Management (PM) framework. The combination of SD and PM has been debated by two converging streams of literature [12]: (1) a dynamic resource-based view [19-22]; and (2) a dynamic view of performance management [12,23,24]. These two approaches both represent strategic resources as "stocks". These variables are subjected to accumulation/depletion processes, which characterize the state of the system [17]. An example could be "equity": it is a variable measured in money, and which can be observed at a given moment in time.

However, while a dynamic resource-based view concentrates the analysis on these variables, and the relative models are designed based on the building up and decline of key core assets, a dynamic performance management view approaches the system analysis by identifying both end-results and performance indicators [12].

End-results are typically represented as "flows". A flow is what changes the stock over a period of time. Returning to the equity example, one of its flows is "net income". This flow, which can be measured as money divided by time, says how much equity has changed during the time period considered thanks to the business management.

In a DPM view, performance is defined and improved in relation to a specific "product" [25,26] (the term "product" refers to the output of an administrative task and not necessarily to the output of a production function). End-results depend on the intermediate results (monitored through performance indicators) that are causally determined by the use of strategic resources. Performance indicators are usually measured in relative terms by comparing the actual state of a variable with a target value. The gap this comparison creates represents the intermediate result the management should monitor in order to achieve the end-result.

Closing the loop, the achieved end-results feed back to the strategic resources and foster them. The model structure is then obtained by linking the relevant stocks and flows that determine a certain behavior of the system over time [27]. The feedback loops built by following this approach imply that 
the flows affecting strategic resources are measured over a time lag. This makes clear how the delays involved in the resources accumulation process represent a central issue in managing performance in a dynamic and complex environment [12,23] such as the one studied here.

This approach provides a systemic view of a production/provision process since each performance indicator shows how the employment of the linked strategic resources affects all the other interdependent resources within the system [12,23]. Due to this interdependence, each strategic resource has indeed the power to foster, or not, others in the same system. For example, cash affects the number of buses available to the service through new investments, the number of buses available impacts on the distance travelled during year, and this determines the amount of resources the Region will assign to AMAT. Revenues from the Regional service contract increase net income, which, over time, influence the cash value positively.

Figure 1 (that has been realized through iThink 10.0.4 software, isee systems Inc., Lebanon, NH, USA) illustrates the dynamic performance management framework. The analysis starts from the bottom of the diagram, which concerns end-results identification. These are causally related to performance indicators variables, which are represented as auxiliary variables (in black). These indicators represent the intermediate results that explain how the final ones are achieved. Performance indicators depend (causal relationship) on the usage of the strategic resources (square variables). Strategic resources accumulate value when the end-results are achieved and decrease value when they are employed in a new production/provision cycle.

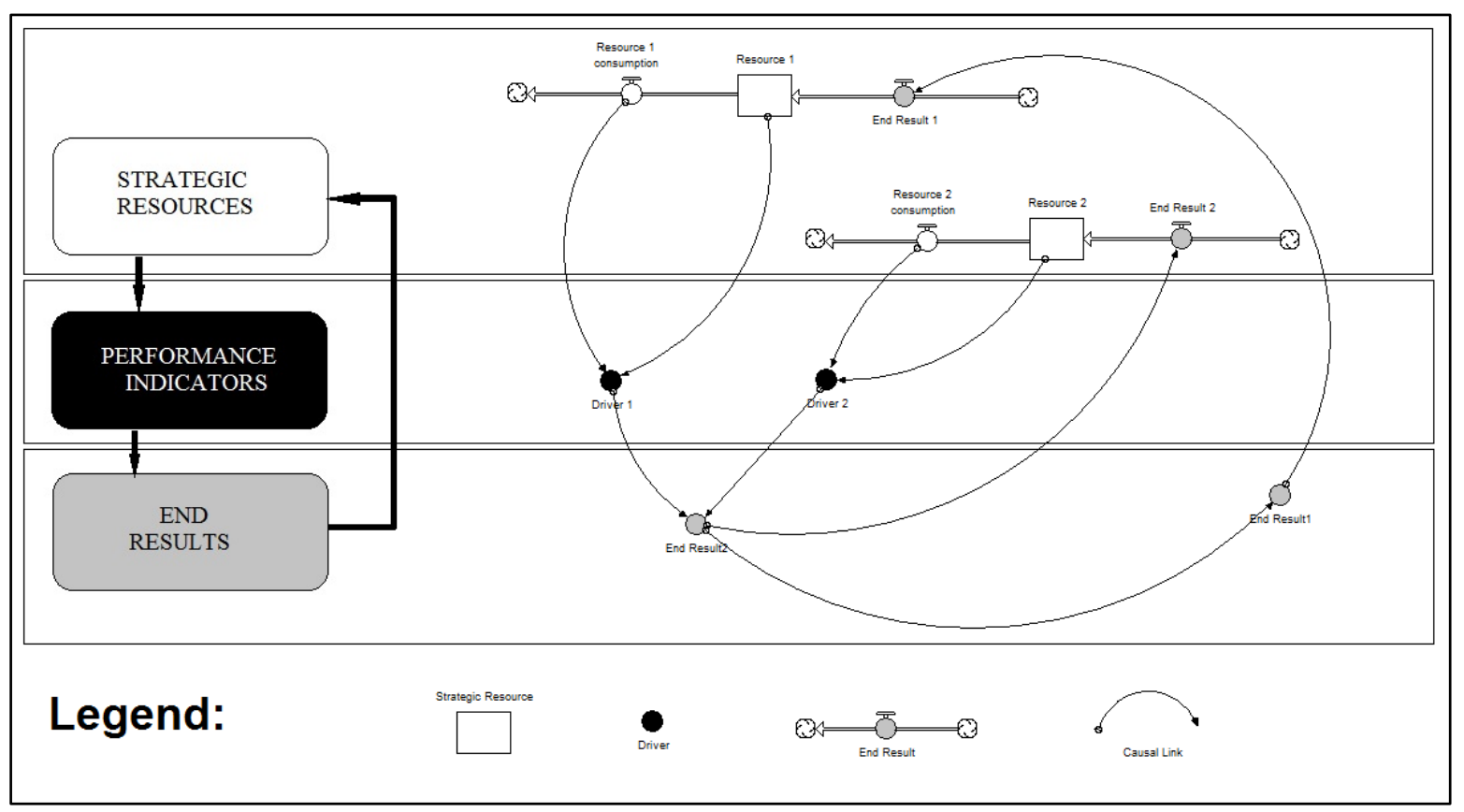

Figure 1. A Dynamic Performance Management view

Since this research develops a case study adopting a Performance Management view, it is important to remark that organizational performance can be articulated in different dimensions [28,29]. Particularly, Coda [28] identifies competitive, financial and social dimensions. This paper focuses specifically on the competitive ones, which represents the process of building critical success factors. 
The approach described above was applied to the case study of Palermo's transportation utility. The aim of the study was to explore a real utility, which experiences dynamic and "wicked" problems. The adopted perspective was a micro one; that means we developed our analysis at company level, focusing specifically on management problems. However, this does not mean we did not consider the inter-institutional structure of the governance; we looked at this through AMAT top management eyes. As a result, we built an SD model and a set of performance indicators that allowed us to run the analysis. The main assumption behind the case study refers to a population that does not change.

The data needed to develop the case and build the model have been collected thanks to open consultations with four AMAT top managers (economic and financial director, human resources director, maintenance department director, and transport service director). These consultations helped in building a qualitative structure of the AMAT model. Once the system was structured, thanks to a deep document analysis (balance sheet from 2008 to 2012, service contracts with Municipality of Palermo and Region of Sicily) a quantitative SD model was built. The reference mode used to conduct the analysis of the system is AMAT's net-income. This choice was made because this variable can represent the performance of the whole system.

\section{Results}

\subsection{The Case of AMAT in Palermo}

The study here presented is based on the local utility providing the urban transportation service in Palermo: AMAT. Since the year 2005, AMAT is a joint stock company in which the Municipality of Palermo holds $100 \%$ of shares. On the one hand, being formally private, the company is accountable for its economic and financial performance; on the other hand, AMAT faces several constraints coming from the service contracts stipulated with both the Municipality — which imposes significant personnel policies - and the Sicilian Region (i.e., the Region decides how much to pay the utility together with the minimum ticket price they may charge the citizens).

Figure 2 synthesizes the multi-level governance structure in which the utility operates.

In Italy, regions constitute the second level of public administrations. The Sicilian Region influences the utility activities both directly (by deciding the ticket price) and indirectly (by transferring funds to the municipality that have to be devoted to urban transportation). The Municipality of Palermo, on its side, corresponds a fixed amount of funds to AMAT every year. On the other side, holding $100 \%$ of the utility shares, the economic results of AMAT influences results and strategies of the Municipality itself. At the bottom of the governance structure presented in Figure 2, we find the community, i.e.: citizens and visitors. AMAT provides the service to them and if it does not match their expectations, this will badly influence both the utility performance in terms of ticket sold, and the others governance levels (the Municipality one in particular) when election time comes. 


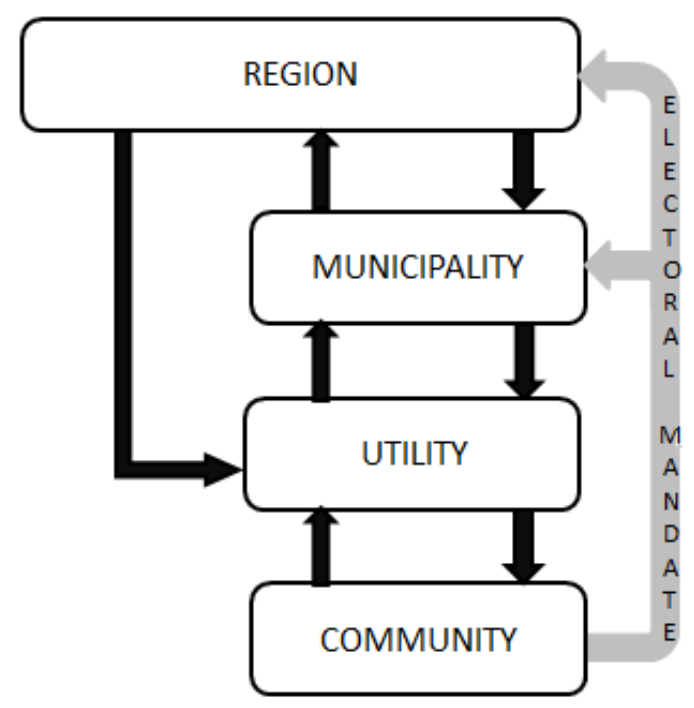

Figure 2. Governance structure.

When building a model upon this case, we need to take into account the governance structure displayed above since it influences and sometimes generates, important causal relationships responsible for the system's behavior [23,30,31].

The model was built with the aim of simulating the economic performance of AMAT over the last five years. A model able at simulating AMAT performance behavior would allow us to understand the company system structure. It would be possible to analyze where and how the wicked problems that AMAT faces originate. Connections among governance levels would be made explicit through causal relationships and, once the performance indicators will be identified, it will be clear what influence each of those, and how.

The model building process followed two steps. First of all, a Causal Loop Diagram (CLD) was sketched in order to represent the causal relationships affecting the system emerged from the top management interviews. CLD is a tool aimed to show the loop characterizing a system. Then, after a documents analysis and data extrapolation, a Stock and Flow (SF) model was built. SF structure is needed in order to identify strategic resources, and related performance indicators. Also, SF diagram allows one to simulate the results of the analysis. As the model building process is iterative, the formulation of the SF model helped in testing and adjusting the first CLD sketch. The variable chosen as reference mode for this case study is AMAT net income. This represents the main result, which the management monitors and aims to achieve, and it is computed as the residual of all revenues and gains over all expenses and losses for the period [32].

\subsection{Causal Loop Diagram}

Through the CLD, it is possible to identify the system feedback loops responsible for AMAT performance behavior. Each link constitutes a hypothesis based on the top management consultation and on the financial accounting reporting system [33]. In figure 3, the CLD with the identification of the main loops is displayed. The diagram has been sketched through Vensim PLE software (Ventana System Inc., Harvard, MA, USA). 
Figure 3 shows three main reinforcing loops related to the dynamics generating revenues, and two balancing loops concerning the origins of costs. Additionally, two more reinforcing loops show the feedbacks from the community to the service quality standard, while another balancing loop refers to debts. Reinforcing and balancing are not synonymous of positive and negative. Reinforcing loops are loops that feed themselves, leading to exponential behaviors: the growth (decline) of a certain variable affects the growth (decline) of another one, which, after a time delay, increases (decreases) the value of the first. Balancing loops, on the other hand, are loops that drain themselves and tend to settle the system toward a specific value. The dominance of the different loops over time, determines the system behavior.

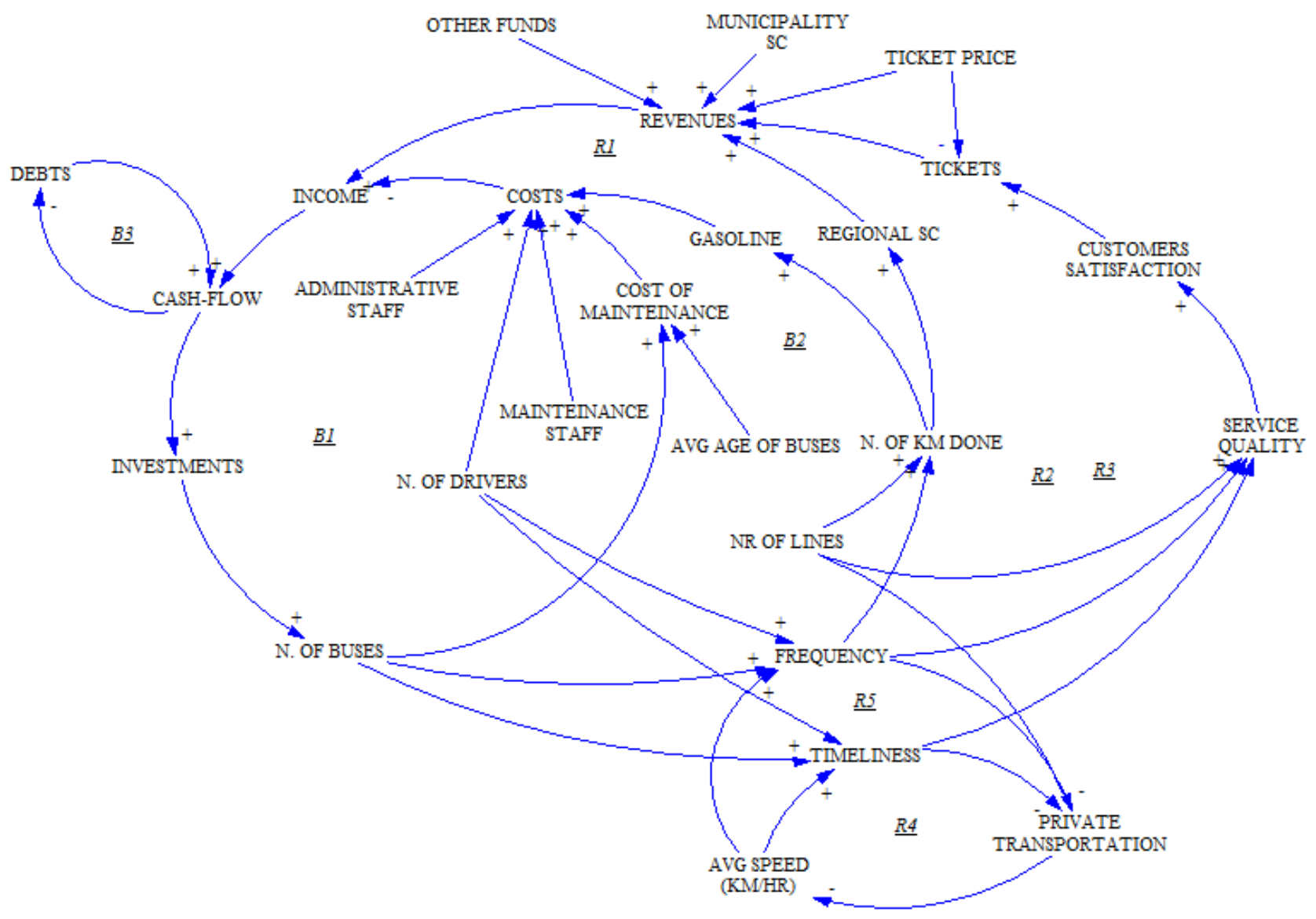

Figure 3. Causal Loop Diagram

In Figure 3, Rs and Bs identify the systems' loops. R stands for "reinforcing" and B for "balancing". $\mathrm{R} 1$ loop shows how net income is connected to cash flow; a positive cash flow gives the company the possibility to invest in new buses. The presence of new buses makes the company able to provide the service with more frequency. This directly impacts on the number of km travelled every year which, based on the service contract with the Sicilian Region, determines the amount of funds the same Region would allocate to AMAT for its service. These funds are one of the main determinants of company's revenues, and the base for net income.

B1 loop represents the dynamic by which an increase in number of buses-determined by cash availability and, therefore, incomes - increases, over time, the cost of maintenance, which will be added to the total cost the company yearly incurs. Total cost is the negative component of the net income. 
B2 loop represents the higher cost the company incurs in when number of km travelled per year grows. In fact, when number of $\mathrm{km}$ travelled increases, due to a bigger frequency related to an increase in the number of buses available, total cost of gasoline increases.

B3 loop shows the company debt policy. Simply, whenever the cash flow goes below zero, AMAT management is willing to increase its debt. While every time the cash flow is positive, AMAT management is willing to use part of it to reduce its debt.

$\mathrm{R} 2$ and R3 loops represent the dynamics relative to the citizens/customers' satisfaction. These loops were built based on the hypothesis that customers' satisfaction mainly depends on the extensiveness of service, its frequency and its timeliness. An improvement of service in these directions would determine an improvement in quality as perceived by citizens and customers. As the perceived quality of service increase, customers' satisfaction will grow and revenues coming from ticket sale will increase. This will positively affect net income, which, determining the cash level, may allow the manager to invest in new buses in order to ensure a better service quality.

Concluding, R4 and R5 loops show how an increase in service timeliness and frequency may cause, over time, a reduction in private transportation and so in traffic congestion, which will allow buses to run faster and more frequently.

A last comment on the CLD regards the boundaries of the system, that is to say, the variables considered exogenous (namely, variables not influenced by any other factor within the system). This study considers exogenous the number of bus lines, ticket price, the revenues coming from the municipality service contract and a variable directly impacting on the cash flow: other funds.

The number of lines is determined unilaterally by the Municipality, while the ticket price is decided by the Sicilian Region.

The reasons why the municipality service contract has been considered exogenous reside in the fact that this contract is characterized by a fixed amount of money that does not change in base of any parameters.

Other funds represent not-planned funds coming from "external" actors such as the European Union (this is what happened in 2011, where $€ 20$ million FAS funds were attributed to AMAT by the Municipality in order to buy new buses).

A particular remark is due in explaining the decision-making process regarding personnel area. As the reader may notice, the staff variables are not affected by any others. This could sound curious since, being "Labor" one of the components of any production function, total staff should receive at least a feedback from the activity size. What surprised us in this case study, is that, due to the Municipality influence and to the Italian Stability Pact (Articles 550-569 of the Italian Law n.147/2013), the top management is not allowed to modify human resource availability when needed.

\subsection{Stock and Flow Model}

The conversion from a CLD to a SF model is a necessary step to do for conducting the performance analysis and for simulating the results of the structural analysis conducted above.

The simulations results are portrayed in Figure 4. The simulations have been realized through iThink 10.0.4 software (isee systems Inc., Lebanon, NH, USA). 


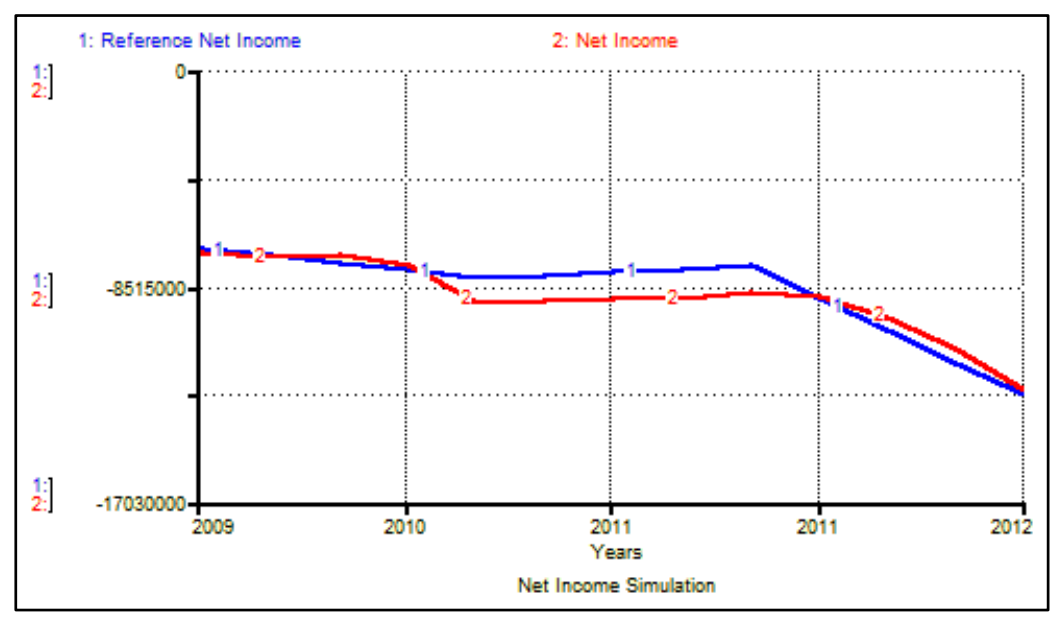

Figure 4. Simulation.

Line 1 (Reference Net Income) represents the historical data taken from the official balance sheets (2009-2012). Line 2 (Net Income) represents the result of the model simulation. As we may notice, the company has encountered a dynamic problem, which consists of a declining net income.

Replicating the system behavior with a low deviation from the historical data is important but it is not enough to demonstrate the reliability of the model. Therefore, some other tests (structure verification test, extreme condition test and sensitivity analysis) have been conducted in order to validate the model [34]. Also, once the model was built, further discussions on its structure were conducted with the economic and financial director in order to get feedback and further insights on the case study.

The SF model structure (Figure 6) differs from the CLD in one aspect: It was not possible to find a reliable measure of timeliness, so this variable was integrated in the frequency measure.

In Figure 5, the different system variables previously identified have been developed and framed into three kinds of variables: strategic resources, performance drivers and end-results.

This framework allows one to read the causal relationships of the system by adopting a Dynamic Performance Management perspective [23].

Figure 6 shows a simplified version of the structure built to simulate the behavior in Figure 4 .

Performance drivers are represented as round shaped symbols. These are measured in relative terms by comparing the actual organizational performance and a target value fixed by the company (i.e., Desired Distance Travelled) or a benchmark, [29] (e.g., Average Age of Bus). The indicators here identified belong to the competitive dimension of performance [28], which is to say, they are specifically oriented at monitoring how AMAT is able to satisfy the market needs.

Grey circles are indicators that are not under the full control of AMAT management, while white ones are indicators that are mainly influenced by the company management. 


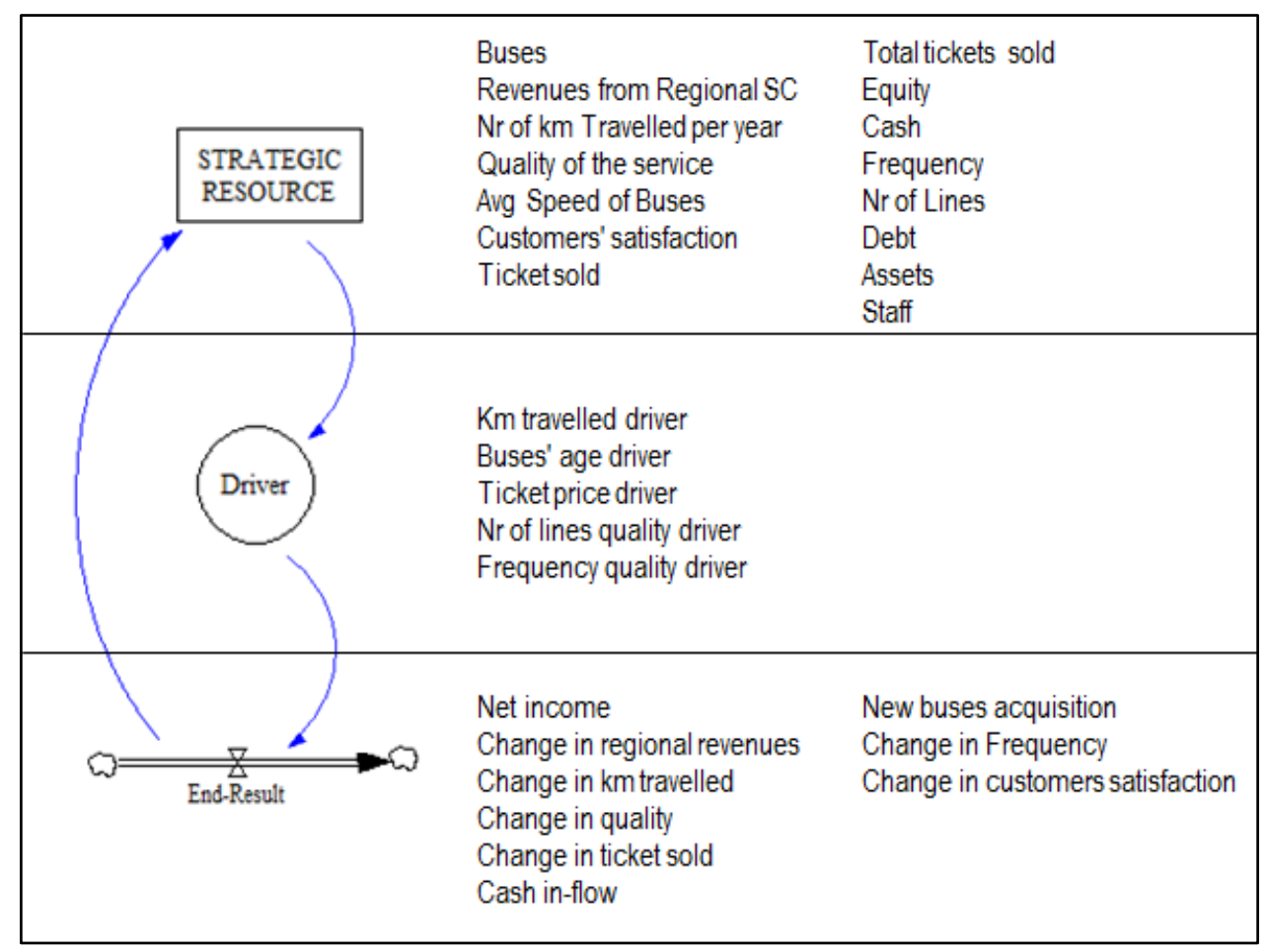

Figure 5. A DPM approach for the AMAT case.

Figure 6 shows the same loops portrayed in Figure 3. The diagram has been sketched through Vensim PLE software (Ventana System Inc., Harvard, MA, USA). Revenues and expenses determine net income. Once collected (or paid), these impact on the cash level. Cash inflow and outflow are also determined by debt increase or payment. Cash can be invested in new assets. The assets level may decrease for disinvestments (which increase the cash level) or by depreciation. Part of the total investment in assets is devoted to increasing the number of buses available. An increase in buses has different effects: company maintenance costs rise; average bus ages lower, reducing the cost of maintenance per bus; and it impacts, together with the number of bus drivers, on the frequency of service.

Frequency of service, on the one hand, increases the number of $\mathrm{km}$ travelled, which determines the fuel costs (expenses) and the revenues from the regional service contract (revenues). On the other hand, frequency represents a quality standard: it discourages the use of private transportation that causes road congestion and may limit the ability of buses to perform a desired frequency; it impacts, together with the number of lines, on the quality of service that determines customer satisfaction and, therefore, the number of tickets sold (revenues). 


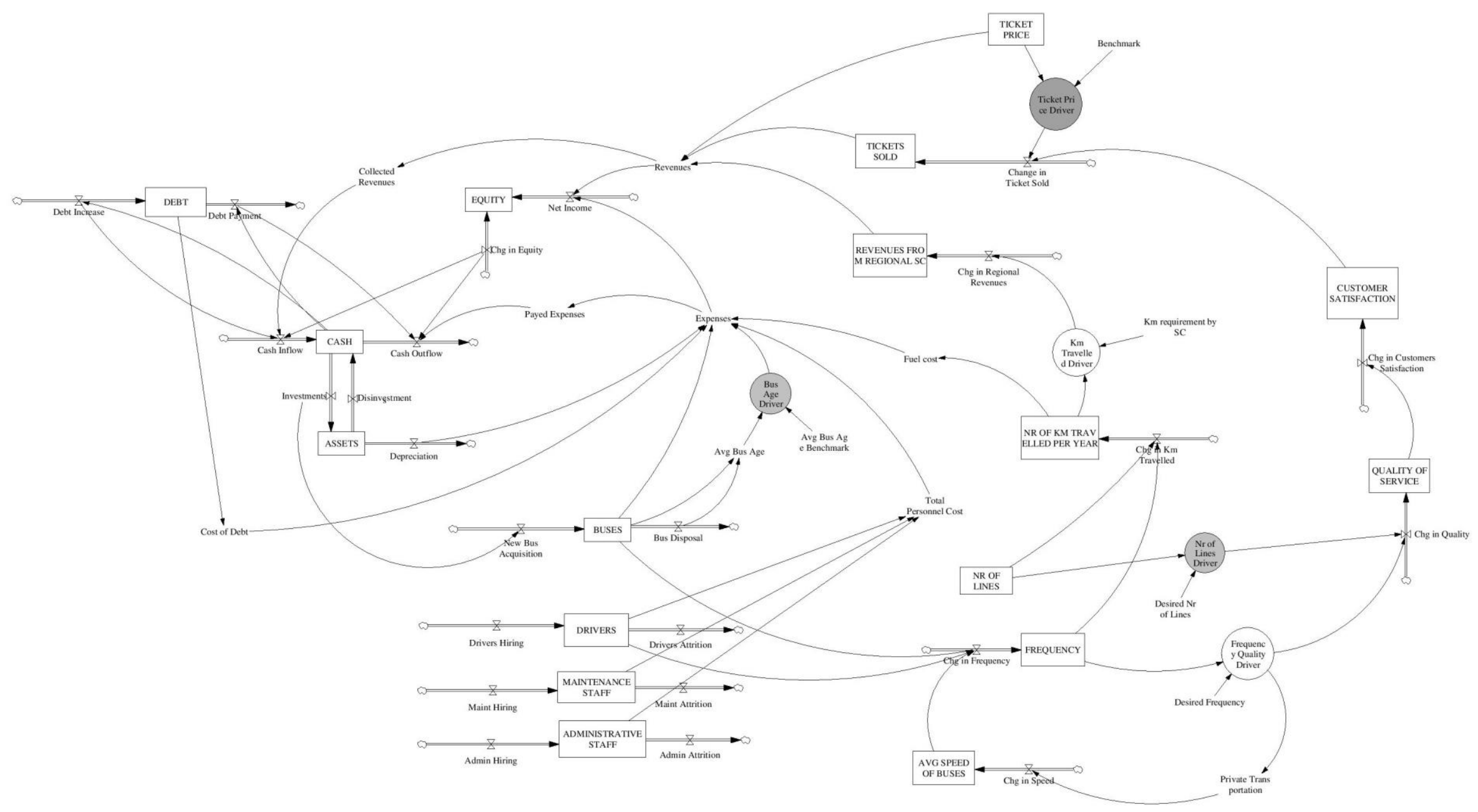

Figure 6. Stock and Flow model structure. 


\section{Discussion}

This Section goes further in depth into discussing the identification of performance indicators and, as guided by the research questions of this paper, examining who-among AMAT, Municipality of Palermo and Region of Sicily — has the lever of control for each of them. The set of indicators has been built following the DPM approach adopted here. The end-results that drove the definition of performance indicators (net income, change in regional revenues, change in ticket sold, change in $\mathrm{km}$ travelled, change in quality of the service, change in frequency, new buses acquisition, and cash flow) have been identified through top-management consultations.

\subsection{Indicator 1: Distance Travelled}

This indicator has been built by comparing distance travelled (measured in number of $\mathrm{km}$ ) by the company's buses during the year, with the distance requested by the Municipality and the Region in order to perform the service contracts duties. Given the company resources, this is an effectiveness indicator that shows AMAT's ability to perform a specific service requirement.

Distance travelled depends on extensiveness (number of lines) and frequency of service. Given the resources in terms of buses and drivers, it is AMAT having a major role in ensuring a satisfying frequency of lines to offer to customers. Therefore, this indicator could be considered under AMAT management control.

\subsection{Indicator 2: Buses' Age}

Buses' age indicator impacts directly on cost of maintenance. Buses younger than five year cause an ordinary cost of maintenance (i.e., filters, oil, etc.), whereas non-ordinary costs (i.e., engine repair) are at the expenses of bus suppliers. However, buses older than five years determine a bigger cost for AMAT, since it is in charge of both ordinary and non-ordinary costs. This intermediate result is affected by the investment rate (bus purchase rate). The investment rate appears mainly determined at a municipal level (through the allocation of specific funds). Therefore this indicator depends on both AMAT and its shareholder.

\subsection{Indicator 3: Ticket Price}

Ticket price, as microeconomic literature may support, has a direct impact on the demand of service. The minimum ticket price is determined by the Sicilian Region. The company is allowed to apply a lower price only if the municipality guarantees to pay out the difference between the two prices multiplied by the number of tickets sold during the year. This means the company cannot modify the ticket price in relation to the demand variation. Hence, this indicator is not under AMAT top management control, which is not accountable for the dynamics coming from the ticket price.

\subsection{Indicator 4: Number of Lines}

The extensiveness of service was measured as the number of lines the company offers. Today, AMAT service runs through ninety lines. From the top management interview emerged how this number is 
mainly affected by the political sphere. Politicians impose the presence of many non-remunerative lines in order to ensure the public service to citizens. Therefore, this indicator cannot be considered under the company management control; AMAT is not able to decide how many and which lines to provide to citizens/customers.

\subsection{Indicator 5: Frequency}

This indicator is measured as a ratio between the actual service's frequency and the desired one. Frequency quality ratio is an indicator of effectiveness, and measures the ability of the company at optimizing its resources (buses and drivers) in order to ensure as much frequency as possible. Also, the average speed of buses can be considered under the sphere of control of AMAT because, in addition to manage urban public transportation, the company manages road signs in the municipal area. However, there is no clear integration of the two services. Adding a loop that considers the company's ability to intervene in the average speed of buses through road signs management could represent a possible policy in order to improve AMAT system. These considerations lead to the conclusion that AMAT is accountable for this performance indicator.

\subsection{Findings on Managerial Autonomy}

What emerges from the indicators analysis is that, when one of them is depending on a resource owned or controlled by other players of the system, which do not receive any feedback from the system itself (see ticket price or number of lines), then, the management cannot be considered fully accountable for that particular indicator. The more "endogenized" is the resources in the system (that is to say, the stronger are the feedbacks a resource gets from the system), the more the management can effectively intervene on the connected performance driver.

In this case, three out of five indicators are mainly dependent on other governance levels. This situation, which is pretty common in organizations providing public services, makes the different governance players managing the resources under their control solely to pursue their individual aims. The set of indicators provided would inform these actors about how the system works and therefore encourage them to adopt a systemic view. This would facilitate the alignment of aims between the various stakeholders, which is the first step for pursuing the coordination claimed by the joint-up government theory.

In order to foster coordination, it is therefore necessary to reform the system structure so that the external strategic resources (such as ticket price) can get feedbacks from the system itself; like that, new loops will be added to the system "endogenizing" new processes relevant for the service provision. This structural change is based on communication and information exchange between stakeholders owning strategic resources. Figure 7 (realized through Vensim PLE software, Ventana System Inc., Harvard, MA, USA) explains this process of "endogenization" of resources by the system providing an example based on the case study.

$\mathrm{R} 2$ is one of the loops representing the dynamics relative to citizen/customer satisfaction. This loop is based on the hypothesis that customer satisfaction depends on the frequency of service. A service improvement in these directions would lead to an improvement in quality, as perceived by citizens and customers. As the perceived quality of service increase, customers' satisfaction will grow and ticket sale 
revenues will also increase. This will positively affect net income. Tickets sold is a strategic resource influenced not only by customer satisfaction but also by ticket price level. Ticket price value is a strategic resource controlled by the Sicilian Region. This governance level does not get any feedback from the company performance (in terms of tickets sold) in order to decide how much to charge citizens for a ticket. Adding a new causal link (dashed in the above figure) and a new flow (italic and underlined) to the existent structure would give the Sicilian Region the possibility to intervene on this variable more consciously and take into consideration the effects on the whole system. With this new link, we then create a new feedback loop (B4) that strengthens the coordination between the governance levels involved, now able to jointly intervene on the "ticket price" indicator.

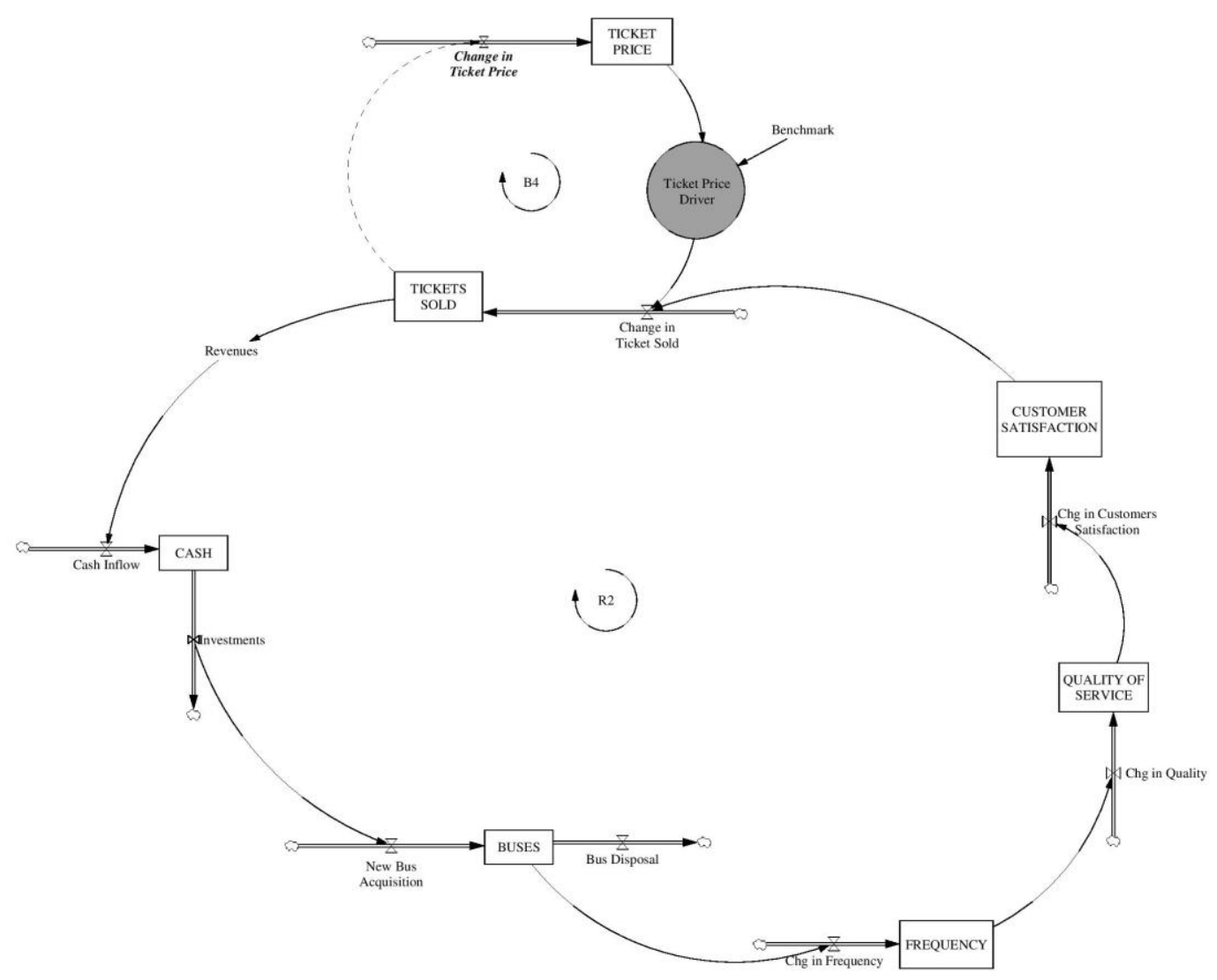

Figure 7. "Endogenization" process.

\section{Conclusions and Research Perspectives}

Multi-level governance is characterized by the inter-playing of different actors in a production/provision process. In a multi-level governance structure, various stakeholders influence the system since they control one or more of its specific strategic resources.

The problems that arise in this kind of structures are related to the different goals, interests and values that these stakeholders have in respect to the product/service outcome. This situation not only leads to 
contradiction and tension between different policies and action programs, but primarily prevents stakeholders from agreeing on the definition of problems.

This paper has provided a case study concerning the service of public urban transportation in the Municipality of Palermo.

The adopted approach, i.e., Dynamic Performance Management, allowed us to understand who the governing players are, their roles, and how they influence the production and provision processes. As "all models are wrong" [35,36], in the sense that our knowledge about a complex system is limited and therefore we need to simplify our models in order to represent the complexity within them, this consideration helps us to distinguish between the model and the reality it attempts to represent. Even if the model is "wrong", in the sense that a model cannot represent all the details present in the real world, its usefulness comes from helping us understand the main causal relationships that form the system structure. The model allowed us to build a set of performance indicators that help us to understand the impact of the governing structure on the system's performance. These indicators can inform stakeholders about how the system works (how end-results are achieved), allowing them to develop shared understanding and meaning about any problems that arise. The indicators may help in reforming the system through improved coordination of the actors involved in governing it, thus reducing the wickedness of the production process. Overall, the model can be used as a tool for engagement and communication with other levels of governance.

Further development of this research could actually be to build some feedback structures relating the company performance to the strategic resources not included in the system structure. These feedbacks would help in considering the system as a whole, overcoming the fragmentation characterizing the governance. This approach should lead to "better" results and therefore, may be useful in dealing with wicked problems generated by the multi-level governance structure. Through simulation in the medium-long term, it will be possible to test such feedback structures.

On the basis of the analysis here presented, it seems realistic to expect further improvements in this research according to the logical framework adopted.

\section{Acknowledgments}

This paper is a further development of the conference paper "A Dynamic Performance Management Approach to Foster Coordination Between Multi-level Governance Bodies: A Urban Transportation Case Study" presented at Euro Mediterranean Dialogue on Public Management, MED7, Rome, Italy, 8-10 October 2014.

The authors would like to thank the reviewers for their useful and constructive comments.

\section{Author Contributions}

The conceptual structure of this paper has been outlined by Guido Noto under the scientific supervision of Carmine Bianchi. Based on such conceptual structure, Guido Noto has built the System Dynamics model. Discussion of the results and implications from the model has been jointly developed by the two authors. 


\section{Conflicts of Interest}

The authors declare no conflict of interest.

\section{References}

1. Hood, C. A Public Management for All Season? Public Adm. 1991, 69, 3-19.

2. Anselmi, L. Il Processo di Trasformazione Della Pubblica Amministrazione. Il "Percorso Aziendale”; Giappichelli: Torino, Italy 1995.

3. Rebora, G. Un Decennio di Riforme. Nuovi Modelli Organizzativi e Processi di Cambiamento delle Amministrazioni Pubbliche (1990-1999); Guerini e Associati: Milano, Italy, 1999.

4. Lioukas, S.; Bourantas, D.; Papadakis, V. Managerial Autonomy of State-Owned Enterprises: Determining Factors. Org. Sci. 1993, 4, 645-666.

5. Christensen, T.; Laegreid, P. The Whole-of-Government Approach to Public Sector Reform. Public Adm. Rev. 2007, 67, 1059-1066.

6. Lo Bue, M. From Fiscal Compact to the United States of Europe: Some Remarks on a Difficult Pathway. Available online: http://ssrn.com/abstract=2400353 (accessed on 29 June 2015).

7. Head, B.W.; Alford, J. Wicked Problems: Implications for Public Policy and Management. Adm. Soc. 2013, 10.1177/0095399713481601.

8. Pollit, C. Joined-Up Government: A Survey. Polit. Stud. Rev. 2003, 1, 34-49.

9. Rittel, H.W.J.; Webber, M.M. Dilemmas in a General Theroy of Planning. Policy Sci. 1973, 4, 155-169.

10. Australian Public Service Commission. Tackling Wicked Problems: A Public Policy Perspective; Commonwealth of Australia: Barton, Australia, 2007.

11. Ling, T. Delivering Joined-Up Government in the UK: Dimensions, Issues and Problems. Public Adm. 2002, 80, 615-642.

12. Bianchi, C.; Marinković, M.; Cosenz, F. A Dynamic Performance Management Approach to Evaluate and Support SMEs Competitiveness: Evidences from a Case Study. In Proceedings of the XXXI International Conference of the System Dynamics Society, Cambridge, MA, USA, 21-25 July 2013.

13. Bianchi, C.; Montemaggiore, G.B. Enhancing strategy design and planning in public utilities through "dynamic" balanced scorecards: Insights from a project in a city water company. Syst. Dyn. Rev. 2008, 24, 175-213.

14. Ackoff, R.L. Redesigning the Future: A Systems Approach to Societal Problems; John Wiley \& Sons: New York, NY, USA, 1974.

15. Hjorth, P.; Bagheri, A. Navigating towards sustainable development: A system dynamics approach. Futures 2006, 38, 74-92.

16. Richmond, B. System dynamics/systems thinking: Let's just get on with it. In Proceedings of the International Systems Dynamics Conference, Sterling, Scotland, 11-15 July 1994.

17. Sterman, J.D. Business Dynamics: System Thinking and Modelling for a Complex World; McGraw-Hill: London, UK, 2000.

18. Forrester, J.W. Industrial Dynamics; MIT Press: Cambridge, MA, USA, 1961. 
19. Morecroft, J. The Rise and Fall of People Express: A Dynamic Resource-Based View. In Proceedings of the 15th International Conference of the System Dynamics Society, Instanbul, Turkey, 19-22 August 1997.

20. Morecroft, J. Strategic Modeling and Business Dynamics; John Wiley \& Sons: Chirchester, UK, 2007.

21. Warren, K. Competitive Strategy Dynamics; John Wiley \& Sons: Chirchester, UK, 2002.

22. Warren, K. Strategic Management Dynamics; John Wiley \& Sons: Chirchester, UK, 2008.

23. Bianchi, C. Enhancing performance management and sustainable organizational growth through system-dynamics modelling. In Systemic Management for Intelligent Organizations; Grösser, S.N.; Zeier, R., Eds; Springer: Berlin, Germany, 2012; pp. 143-161.

24. Bianchi, C.; Rivenbark, W. Using System Dynamics to Enhance Performance Management in Local Government: An Application to Residential Refuse Collection. In Proceedings of the 2012 APPAM Fall Research Conference, Baltimore, MD, USA, 8-10 November 2012.

25. Bianchi, C. Improving Performance and Fostering Accountability in the Public Sector through System Dynamics Modelling: From an "External" to an "Internal" Perspective. Syst. Res. Behav. Sci. 2010, 27, 361-384.

26. Bianchi, C.; Bivona, E.; Cognata, A.; Ferrara, P.; Landi, T.; Ricci, P. Applying System Dynamics to Foster Organizational Change, Accountability and Performance in the Public Sector: A Case-Based Italian Perspective. Syst. Res. Behav. Sci. 2010, 27, 395-420.

27. Cosenz, F. A System Dynamics Approach to Analysing the Effect of Clientelism on Public Organizations Performance in Italy. Rev. Int. Comp. Manag. 2010, 11, 325-337.

28. Coda, V. Entrepreneurial Values and Strategic Management: Essays in Management Theory; Palgrave Macmillan: Basingstocke, UK, 2010.

29. Eccles, R. The Performance Measurement Manifesto. Harv. Bus. Rev. 1991, 71, 131-137.

30. Bivona, E.; Montemaggiore, G.B. Understanding short- and long-term implications of "myopic" fleet maintenance policies: A system dynamics application to a city bus company. Syst. Dyn. Rev. 2010, 26, 195-215.

31. Winch, G.W. Three System Dynamics Cases Addressing the Challenge in Performance Improvement in the Public Sector. Syst. Res. Behav. Sci. 2010, 27, 421-424.

32. Stickney, C.; Weil, R.; Schipper, K.; Francis, J. Financial Accounting: An Introduction to Concepts, Methods, and Uses; Cengage Learning: Mason, OH, USA, 2009.

33. Melse, E. The Financial Accounting Model from a System Dynamics' Perspective. Available online: http://dx.doi.org/10.2139/ssrn.1081620 (accessed on 29 June 2015).

34. Barlas, Y. Formal Aspects of Model Validity and Validation in System Dynamics. Syst. Dyn. Rev. 1996, 12,183-210.

35. Sterman, J.D. All models are wrong: Reflections on becoming a systems scientist. Syst. Dyn. Rev. 2002, 18, 501-531.

36. Meadows, D. The Unavoidable a Priori. In Elements of the System Dynamics Method; Randers, J., Ed.; Pegasus Communications: Waltham, MA, USA, 1980.

(C) 2015 by the authors; licensee MDPI, Basel, Switzerland. This article is an open access article distributed under the terms and conditions of the Creative Commons Attribution license (http://creativecommons.org/licenses/by/4.0/). 